\title{
Serotonin $\left(5-\mathrm{HT}_{3}\right)$ receptor antagonists for the reduction of symptoms of low anterior resection syndrome
}

This article was published in the following Dove Press journal:

Clinical and Experimental Gastroenterology

II March 2014

Number of times this article has been viewed

\section{Ryohei Itagaki \\ Keiji Koda \\ Masato Yamazaki \\ Kiyohiko Shuto \\ Chihiro Kosugi \\ Atsushi Hirano \\ Hidehito Arimitsu \\ Risa Shiragami \\ Yukino Yoshimura \\ Masato Suzuki}

Department of Surgery, Teikyo University Chiba Medical Center Anesaki, Ichihara, Chiba, Japan
Correspondence: Keiji Koda

Department of Surgery, Teikyo University Chiba Medical Center, 3426-3 Anesaki,

Ichihara, Chiba 299-0I II, Japan

$\mathrm{Tel}+8 \mid 43662$ I2II

Fax $+8|4356| 396 \mid$

Email k-koda@med.teikyo-u.ac.jp
Purpose: Serotonin (5-hydroxytryptamine [5-HT]) ${ }_{3}$ receptor antagonists are effective for the treatment of diarrhea-predominant irritable bowel syndrome (IBS-D), in which exaggerated intestinal/colonic hypermotility is often observed. Recent studies have suggested that the motility disorder, especially spastic hypermotility, seen in the neorectum following sphincter-preserving operations for rectal cancer may be the basis of the postoperative defecatory malfunction seen in these patients. We investigated the efficacy of 5- $\mathrm{HT}_{3}$ receptor antagonists in patients suffering from severe low anterior resection syndrome.

Patients and methods: A total of 25 male patients with complaints of uncontrollable urgency or fecal incontinence following sphincter-preserving operations were enrolled in this study. Defecatory status, assessed on the basis of incontinence score (0-20), urgency grade (0-3), and number of toilet visits per day, was evaluated using a questionnaire before and 1 month after the administration of the $5-\mathrm{HT}_{3}$ antagonist ramosetron.

Results: All the parameters assessed improved significantly after taking ramosetron for 1 month. The effect was more prominent in cases whose anastomotic line was lower, ie, inside the anal canal. Defecatory function was better in patients who commenced ramosetron therapy within 6 months postoperatively, as compared to those who were not prescribed ramosetron for more than 7 months postoperatively.

Conclusion: These results suggest that 5- $\mathrm{HT}_{3}$ antagonists are effective for the treatment of low anterior resection syndrome, as in diarrhea-predominant irritable bowel syndrome. The improvement in symptoms is not merely time dependent, but it is related to treatment with 5- $\mathrm{HT}_{3}$ antagonists.

Keywords: low anterior resection syndrome, serotonin receptor antagonist, ISR, defecatory malfunction

\section{Introduction}

Over the last 20 years, the anal sphincter-preserving operation (SPO) has replaced abdominoperineal excision, becoming the procedure of choice for rectal cancers located near the anal sphincter. ${ }^{1}$ Even for patients in whom tumors are a definite indication for abdominoperineal excision, intersphincteric resection (ISR) has become an alternative approach with comparable tumor control. ${ }^{2}$ However, postoperative defecatory malfunction inherent to SPO often diminishes the patients' quality of life, especially in those who undergo very low anterior resection (LAR) ${ }^{3}$ or ISR. ${ }^{4}$

One of the major factors associated with postoperative defecatory malfunction is damage to the anal sphincter, which is closely associated with postoperative incontinence. ${ }^{5}$ The severity of incontinence has been scored on the basis of its 
frequency and associated lifestyle alteration. ${ }^{6}$ In addition to postoperative incontinence, patients who undergo SPO often suffer from several other defecatory dysfunctions, such as urgency, incomplete evacuation, and multiple evacuations, collectively known as the "anterior resection syndrome". ${ }^{7}$ The causes of such defecatory malfunctions following SPO have not been well-delineated, although it has been reported that the physiological behavior of the neorectum reconstructed during surgery is one of the factors closely associated with postoperative defecatory malfunction. ${ }^{7}$ Postoperative hypermotility of the neorectum, in particular, may play an important role in the manifestation of multiple evacuations ${ }^{8}$ or urgency. ${ }^{9}$ It may also be associated with the extrinsic denervation of the neorectum caused by surgical maneuvering during the SPO. ${ }^{10-12}$

Diarrhea-predominant irritable bowel syndrome (IBS-D), manifesting as abdominal pain caused by urgency, accounts for one-fourth of the irritable bowel syndrome (IBS) population. ${ }^{13}$ Although the precise mechanism of IBS-D is still unknown, it has been suggested that the symptoms are associated with exaggerated intestinal/colonic motility. ${ }^{14}$ Serotonin (5-hydroxytryptamine [5-HT]), receptor antagonists have been effectively used for the treatment of IBS-D ${ }^{15}$ because of their effects on slowing gut transit. ${ }^{13}$

Postoperative hypermotility of the neorectum following SPO may be one of the causative factors of LAR syndrome, in which patients suffer from severe urgency or incomplete evacuations. The symptoms seen in patients and the background motility disturbance of the colon in the LAR syndrome may, in part, be similar to IBS-D. Under this hypothesis, we conducted the current pilot study to evaluate the efficacy of oral $5-\mathrm{HT}_{3}$ antagonists for the treatment of patients who suffer from severe postoperative defecatory malfunction following SPO.

The study only included male patients who suffered from severe urgency or soiling postoperatively, since it has been reported that male patients often experience more severe defecatory malfunction than female patients when the anastomotic height is very low, as in ISR, ${ }^{16}$ and also because, in Japan, oral 5- $\mathrm{HT}_{3}$ antagonists are accepted treatment options for IBS-D only in male patients.

\section{Patients and methods}

\section{Patients}

Twenty-five male patients (age range, 43-74 years; median age, 60 years) who underwent either LAR $(n=6)$, very LAR $(n=4)$, ISR $(n=13)$, or total proctocolectomy with ileal pouch-anal anastomosis $(n=2)$ for either lower rectal cancer $(n=23)$ or ulcerative colitis $(U C ; n=2)$ were enrolled in the present study. Informed consent was obtained from all patients. Straight sigmoid colon-anal anastomosis using circular staplers was performed in ten of the rectal cancer cases. In the 13 cases that underwent ISR, hand-sewn sideto-end anastomosis, with a short stump $5 \mathrm{~cm}$ from the edge, was performed. Two cases of ileal pouch-anal anastomosis were performed with circular staplers. A laparoscopic operation was performed in one UC case and three LAR cases. A protective ileostomy was constructed in 18 cases $(72 \%)$.

No cases of anastomotic leakage were noted in this series. Four patients received preoperative radiation therapy. The interval between initial surgery or closure of the ileostomy and the time when the $5-\mathrm{HT}_{3}$ antagonist was prescribed was within: 6 months in 16 cases; 7-12 months in three cases; and more than 1 year in six cases. All patients complained of uncontrollable urgency or fecal soiling, despite the usage of several medications at the beginning of this study. Before commencement of administration of the study drug, anticholinergic medications (timepidium bromide hydrate) were being used in seven cases, loperamide in nine cases, Phelloberin (MSD Inc., Tokyo, Japan) in six cases, albumin tannate in four cases, and opium tincture and polycarbophil calcium in one case each. These medicines were continued along with the $5-\mathrm{HT}_{3}$ receptor antagonist during the current study.

\section{Oral 5- $\mathrm{HT}_{3}$ antagonist}

The oral 5- $\mathrm{HT}_{3}$ receptor antagonist used in this study was $5 \mu \mathrm{g}$ of ramosetron hydrochloride (Astellas Pharma Inc., Tokyo, Japan), which was taken once daily after breakfast. In Japan, the recommended dose of ramosetron for male IBS-D cases is $5 \mu \mathrm{g}$ per day, with a maximum dose of $10 \mu \mathrm{g}$ per day. Hence, we used this dose in the current study. Prescribing ramosetron to male patients with suspected IBS-D and to patients with symptoms of LAR syndrome is accepted therapy in Japan. Hence, we did not obtain institutional review board approval before conducting this study.

\section{Evaluation of defecatory dysfunction}

Patients were interviewed using a self-administered questionnaire before and 1 month after commencement of the administration of the oral $5-\mathrm{HT}_{3}$ antagonist. The questionnaire consisted of 20 questions regarding their daily habits, including food preference, alcohol consumption, exercise level, and defecation status, including bowel movement frequency, degree of urgency, multiple evacuations, and degree of incontinence. 
The degree of urgency was classified into four levels as follows: 1 ) severe urgency, score 3 , in which a patient always (more than once a day) could not defer defecation for 10 minutes; 2) moderate urgency, score 2 , in which a patient often (more than once a week) experienced such urgency; 3) mild urgency, score 1 , in which a patient only sometimes experienced such urgency; and 4) no urgency, score 0 , in which a patient was always able to defer defecation for 10 minutes. Patients were deemed to have multiple evacuations if they needed to use the toilet more than three times an hour for completion of evacuation, while "negative for multiple evacuations" was used to describe patients who were able to evacuate satisfactorily each time with one or two toilet visits. The degree of incontinence was scored based on previously reported criteria consisting of five clinical questions that take into account the degree and frequency of incontinence. ${ }^{6}$

\section{Statistical analysis}

Continuous variables were analyzed with the Student's $t$-test. Ordered categories were analyzed with the Wilcoxon signedrank test. All statistical calculations were performed using the SPSS program version 20 (IBM Corporation, Armonk, NY, USA), under the direction of a statistician. A $P$-value of $<0.05$ was considered to indicate statistical significance.

\section{Results}

\section{Changes in defecatory status with the $5-\mathrm{HT}_{3}$ antagonist}

Comparison of the postoperative defecatory status of all cases included in this study before and 1 month after daily intake of ramosetron are shown in Figure 1. The mean Wexner incontinence score decreased from 12.3-9.3 with ramosetron. The mean urgency grade decreased from 2.3-1.2, and the number of defecations per day decreased from 10.8-5.7. All parameters related to defecatory malfunction following SPO improved significantly $(P<0.01)$ after 1 month of ramosetron intake.

\section{Relationship between the effect of the $5-\mathrm{HT}_{3}$ antagonist and anastomotic height in SPO}

Changes in defecatory status with medication were analyzed in terms of the height of the anastomosis. When the anastomotic line was very low and inside the anal canal (ISR or very low $A R, n=17$ ), all parameters improved significantly following the intake of ramosetron chloride for 1 month (Figure 2A-C; $P<0.01$ ). When the level of anastomosis was equal to or higher than the anal canal (such as in the LAR and the UC cases), the urgency score and the number
A

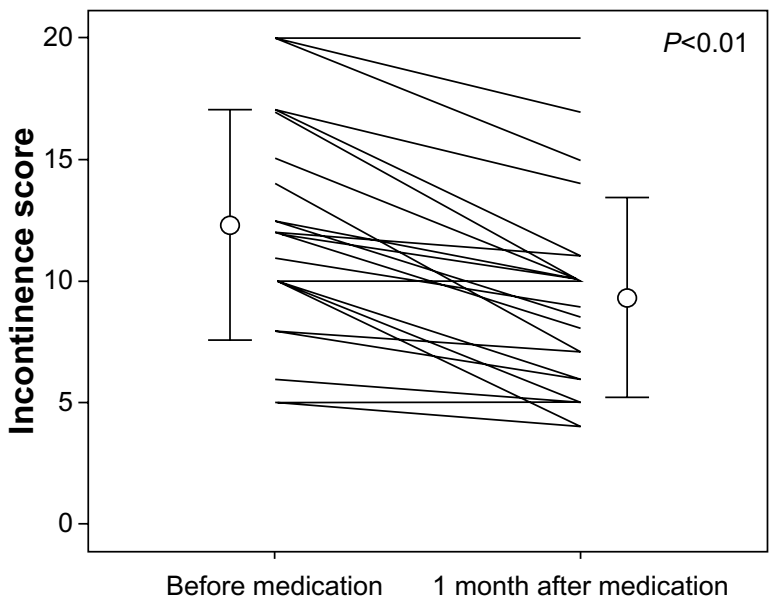

B

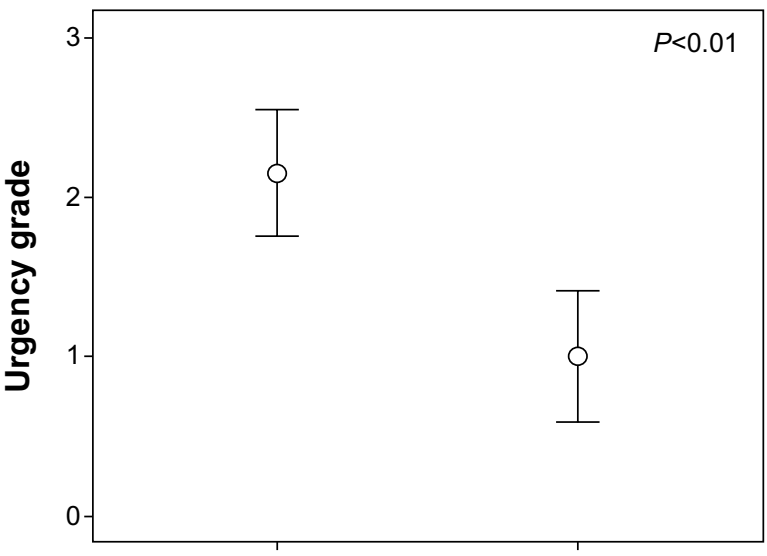

Before medication 1 month after medication

C

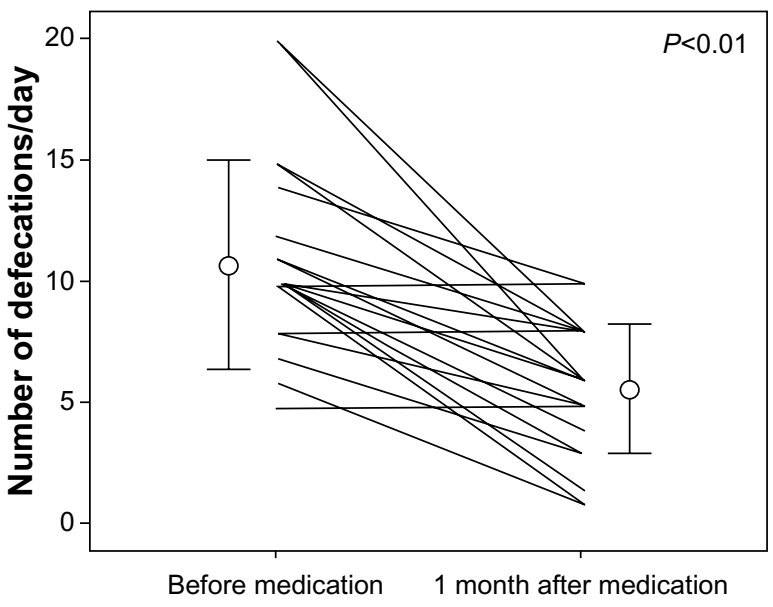

Figure I Changes in defecatory status before and after administration of the $5-\mathrm{HT}_{3}$ antagonist for I month.

Notes: (A) Incontinence score, (B) urgency grade, (C) number of toilet visits per day. Circles and bars indicate mean \pm standard deviation.

of defecations per day were also significantly reduced by medication. However, changes in the incontinence score did not reach statistical significance, although slight improvement was seen in several cases (Figure 2A). 

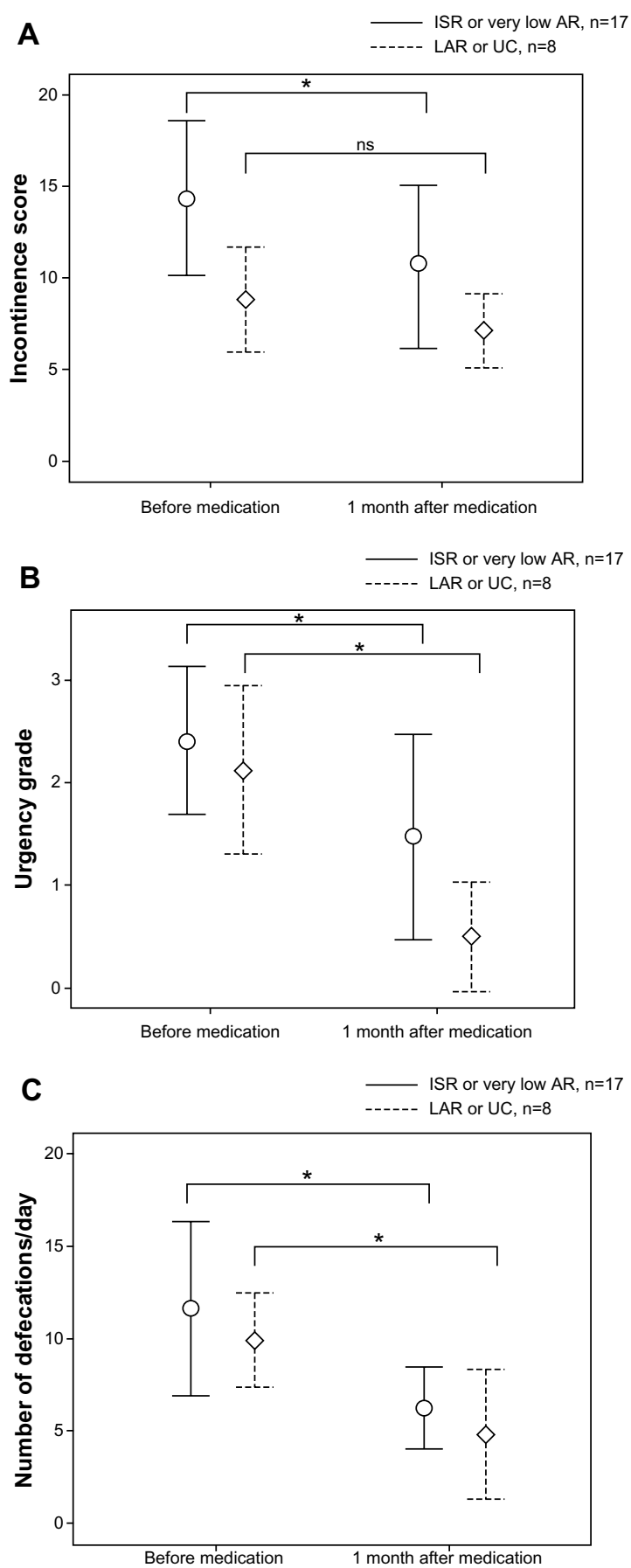

Figure 2 Changes in incontinence scores.

Notes: (A) urgency grade; (B) and the number of toilet visits per day; (C) with $5-\mathrm{HT}_{3}$ antagonist therapy in terms of the level of anastomosis. Values indicate mean \pm standard deviation. $* P<0.01$.

Abbreviations: ISR, intersphincteric resection; AR, anterior resection; LAR, low anterior resection; ns, not significant; UC, ulcerative colitis.

\section{Effect of therapy with the $5-\mathrm{HT}_{3}$ antagonist in terms of duration after operation}

The effect of medication was analyzed in terms of the duration between surgery and the start of the medication. One month of ramosetron intake yielded significant improvements in all the parameters, including the incontinence score, urgency grade, and the number of toilet visits per day - regardless of the duration after the surgery (Figure $3 \mathrm{~A}-\mathrm{C}$ ).

\section{Influence of postoperative time on defecatory status}

To investigate whether the improvement in defecatory status was merely a result of passage of time after surgery, defecatory
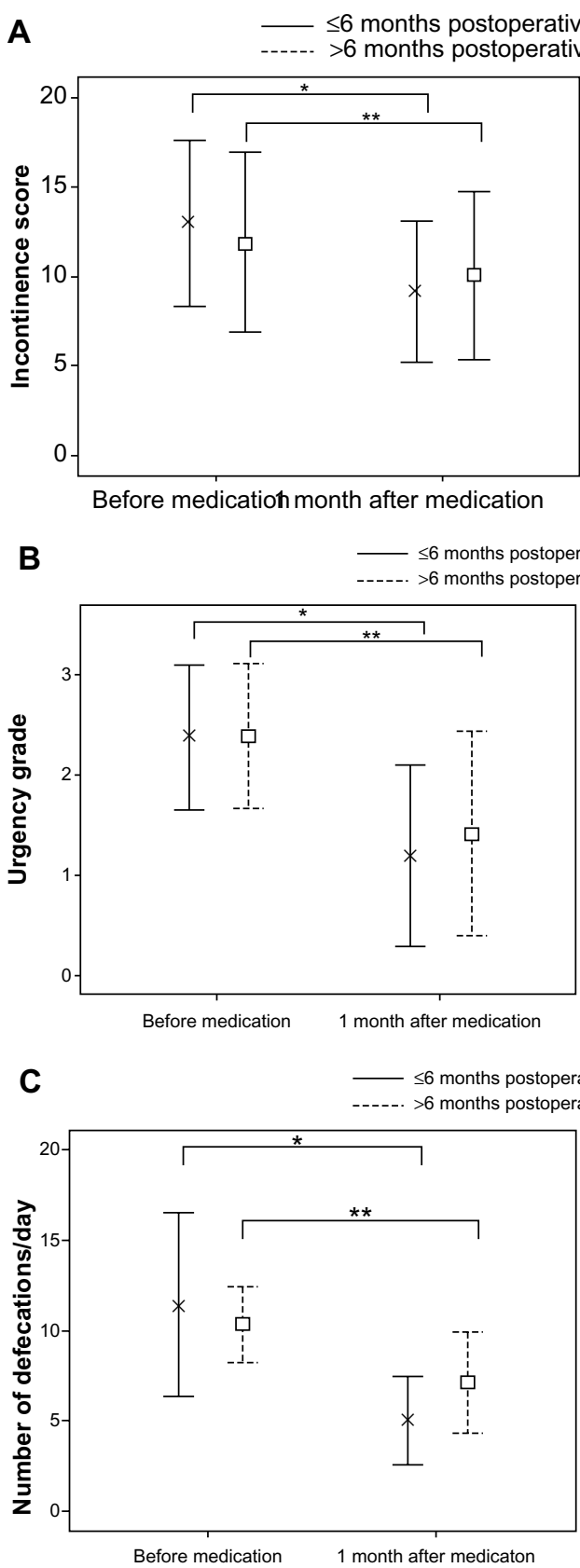

Figure 3 Changes in incontinence scores.

Notes: (A) urgency grade; (B) number of toilet visits per day; (C) with $5-\mathrm{HT}_{3}$ antagonist therapy in terms of the time after the operation. Values indicate mean \pm standard deviation. $* P<0.0$ I; $* * P<0.05$ 
status was compared in two groups: patients who had received medication for 1 month within 6 months postoperatively; and those who had not yet received the medication at more than 6 months postoperatively. As shown in Table 1, urgency grade and the number of defecations per day were significantly better after medication in cases within 6 months postoperatively than those who had not yet received the $5-\mathrm{HT}_{3}$ antagonist at more than 6 months postoperatively. Incontinence scores, however, did not differ between the groups.

\section{Safety and complications of 5- $\mathrm{HT}_{3}$ antagonist therapy}

Among the 25 cases included in this study, three patients stopped taking the medicine after the study period; two were due to constipation 1 month and 2 months following the medication, and the other was due to improvement of symptoms in 9 months. The remaining 22 patients voluntarily continued taking the medicine even after the study, with no side effects.

\section{Discussion}

Defecatory disorders following SPO for rectal cancers or ulcerative colitis are seen in the majority of patients. The severity of symptoms, however, differs from patient to patient. The most severe symptom is incontinence of feces, the degree of which is measured using an incontinence score. ${ }^{6}$ Although not as severe as incontinence, several other symptoms, such as urgency and multiple evacuations, often contribute to lowering the patients' quality of life, especially for those who work outside where frequent usage of the toilet is limited. Therefore, these symptoms, which comprise LAR syndrome, need to be investigated further, in an attempt to ease the patients' burden.

IBS is thought to be a functional disorder that closely correlates with intestinal motility. IBS manifests as several

Table I Comparison of defecatory status

\begin{tabular}{|c|c|c|c|}
\hline & $\begin{array}{l}\text { Medication } \\
\text { prescribed } \\
\leq 6 \text { months } \\
\text { postoperatively } \\
(n=16)\end{array}$ & $\begin{array}{l}\text { Medication } \\
\text { prescribed } \\
>6 \text { months } \\
\text { postoperatively } \\
(n=9)\end{array}$ & $P$-value \\
\hline Incontinence score & $9.19 \pm 3.94$ & $11.89 \pm 5.04$ & $\begin{array}{l}\text { not } \\
\text { significant }\end{array}$ \\
\hline Urgency grade & $1.19 \pm 0.91$ & $2.22 \pm 0.83$ & $P<0.01$ \\
\hline $\begin{array}{l}\text { Number of } \\
\text { defecations/day }\end{array}$ & $5.03 \pm 2.42$ & $10.33 \pm 2.12$ & $P<0.01$ \\
\hline
\end{tabular}

Notes: Defecatory status of patients who received the $5-\mathrm{HT}_{3}$ antagonist within 6 months postoperatively and those who were not prescribed $5-\mathrm{HT}_{3}$ antagonists until more than 7 months postoperatively. Values indicate the mean \pm standard deviation. different types, and some symptoms seen in patients with IBS-D are, to some extent, similar to the symptoms seen postoperatively in patients who undergo SPO for either rectal cancer or UC. Although the precise mechanism of IBS has not been identified, serotonin and 5-HT receptors in the gut may play a major role in the etiology of IBS. ${ }^{17}$ Hence, one of the most commonly used drugs for the treatment of IBS-D is reportedly 5- $\mathrm{HT}_{3}$ antagonists. ${ }^{13}$ Urgency and multiple evacuations are frequently seen in patients with IBS-D, which are similar to the symptoms seen in LAR syndrome. Patients with IBS-D have an increased number of high amplitude contractions, ${ }^{14}$ which may be similar to spastic hypermotility of the neorectum seen in patients with postoperative defecatory malfunction following SPO. ${ }^{9,18}$

Hence, we decided to conduct a pilot study using a 5- $\mathrm{HT}_{3}$ antagonist for the treatment of defecatory malfunction following SPO. Since 5-HT 3 antagonists are only prescribed for male patients in Japan, this study only included male subjects who complained of several types of severe defecatory malfunctions before the administration of a $5-\mathrm{HT}_{3}$ antagonist.

In this study, patients experienced a significant improvement in incontinence score, urgency grade, and the number of toilet visits per day after 1 month of intake of the $5-\mathrm{HT}_{3}$ antagonist. The effect was more prominent in cases with lower anastomotic height and within 6 months postoperatively. However, most of the other patients also experienced improvement in their major symptoms, suggesting a positive effect of $5-\mathrm{HT}_{3}$ antagonists on defecatory disorders regardless of the duration from either initial surgery or closure of the ileostomy. These findings suggest that $5-\mathrm{HT}_{3}$ antagonists are effective for postoperative defecatory dysfunction even in cases with very low anastomotic height, regardless of the timing of induction of the therapy, although with better results if the therapy is commenced within 6 months postoperatively.

Defecatory status usually improves with time after surgery even in patients who undergo ISR. ${ }^{16}$ Despite this, defecatory function was better in patients who started ramosetron intake within 6 months postoperatively than those who had not yet been prescribed the drug for more than 7 months postoperatively. This suggests that improvement in symptoms is not merely time dependent, but it is related to treatment with the $5-\mathrm{HT}_{3}$ antagonist.

In this small pilot study, based on the similarity between symptoms following SPO and those of IBS-D, we administered a $5-\mathrm{HT}_{3}$ receptor antagonist to male patients with severe defecatory malfunction following SPO with favorable results. Since the current study was not a placebo-controlled study 
but a single-arm trial, the positive results seen after taking ramosetron might have been related to a placebo effect, as is occasionally seen in IBS-D cases.

Also, there is a possibility that the other medications the patients were taking may have had confounding effects on the current results. However, judging from the fact that patients had been complaining of severe defecatory dysfunction despite taking several other medicines before starting this study, the positive results seen after the addition of ramosetron seemed to indicate the real effect of the medicine. Further larger studies are warranted to confirm these findings.

\section{Disclosure}

The authors report no conflicts of interest in this work.

\section{References}

1. Pachler J, Wille-Jørgensen P. Quality of life after rectal resection for cancer, with or without permanent colostomy [review]. Cochrane Database Syst Rev. 2012;12:CD004323.

2. Martin ST, Heneghan HM, Winter DC. Systemic review of outcomes after intersphincteric resection for low rectal cancer. Br J Surg. 2012;99(5):603-612.

3. Lewis WG, Martin IG, Williamson ME, et al. Why do some patients experience poor function results after anterior resection of the rectum for carcinoma? Dis Colon Rectum. 1995;38(3):259-263.

4. Denost Q, Laurent C, Capdepont M, Zerbib F, Rullier E. Risk factors for fecal incontinence after intersphincteric resection for rectal cancer. Dis Colon Rectum. 2011;54(8):963-968.

5. Hirano A, Koda K, Kosugi C, Yamazaki M, Yasuda H. Damage to anal sphincter/levator ani muscles caused by operative procedure in anal sphincter-preserving operation for rectal cancer. Am J Surg. 2011;201(4): 508-513.
6. Jorge JM, Wexner SD. Etiology and management of fecal incontinence. Dis Colon Rectum. 1993;36(1):77-97.

7. Bryant CLC, Lunniss PJ, Knowles CH, Thaha MA, Chan CLH. Anterior resection syndrome. Lancet Oncology. 2012;13(9):e403-e408.

8. Fürst A, Burghofer K, Hutzel L, Jauch KW. Neorectal reservoir is not the functional principle of the colonic J-pouch: the volume of a short colonic J-pouch does not differ from a straight coloanal anastomosis. Dis Colon Rectum. 2002;45(5):660-667.

9. Iizuka I, Koda K, Seike K, et al. Defecatory malfunction caused by motility disorder of the neorectum after anterior resection for rectal cancer. Am J Surg. 2004;188(2):176-180.

10. Koda K, Saito N, Seike K, Shimizu K, Kosugi C, Miyazaki M. Denervation of the neorectum as a potential cause of defecatory disorder following low anterior resection for rectal cancer. Dis Colon Rectum. 2005;48(2):210-217.

11. Shimizu K, Koda K, Kase Y, et al. Induction and recovery of colonic motility/defecatory disorders following extrinsic denervation of the colon and rectum in rats. Surgery. 2006;139(3):395-406.

12. Lee WY, Takahashi T, Pappas T, Mantyh CR, Ludwig KA. Surgical autonomic denervation results in altered colonic motility: an explanation for low anterior resection syndrome? Surgery. 2008;143(6):778-783.

13. Spiller RC. Targeting the 5-HT(3) receptor in the treatment of irritable bowel syndrome. Curr Opin Pharmacol. 2011;11(1):68-74.

14. Eshraghian A, Eshraghian H. Intestinal cells of Cajal: a novel hypothesis for the pathophysiology of irritable bowel syndrome. Can J Gastroenterol. 2011;25(5):277-279.

15. Cremonini F, Delgado-Aros S, Camilleri M. Efficacy of alosetoron in irritable bowel syndrome: a meta-analysis of randomized controlled trials. Neurogastroenterol Motil. 2003;15(1):79-86.

16. Ito M, Saito N, Sugito M, Kobayashi A, Nishizawa Y, Tsunoda Y. Analysis of clinical factors associated with anal function after intersphincteric resection for very low rectal cancer. Dis Colon Rectum. 2009;52(1):64-70.

17. Liu HN, Ohya S, Nishizawa Y, et al. Serotonin augments gut pacemaker activity via 5-HT3 receptors. PLoS One. 2011;6(9):e24928.

18. Tabe Y, Mochiki E, Ando H, et al. Correlation between colonic motility and defecatory disorders after anterior resection of the rectum in canine models. Neurogastroenterol Motil. 2008;20(10):1174-1184.
Clinical and Experimental Gastroenterology

\section{Publish your work in this journal}

Clinical and Experimental Gastroenterology is an international, peerreviewed, open access journal, publishing all aspects of gastroenterology in the clinic and laboratory, including: Pathology, pathophysiology of gastrointestinal disease; Investigation and treatment of gastointestinal disease; Pharmacology of drugs used in the alimentary tract;

\section{Dovepress}

Immunology/genetics/genomics related to gastrointestinal disease. This journal is indexed on CAS. The manuscript management system is completely online and includes a very quick and fair peer-review system. Visit http://www.dovepress.com/testimonials.php to read real quotes from published authors. 